G169 ARE CHILDREN AT RISK OF SEVERE INFLUENZA AND ITS COMPLICATIONS RECEIVING PROTECTION FROM SEASONAL FLU?

${ }^{1} \mathrm{D}$ Gokulakrishnan, ${ }^{1} \mathrm{R}$ Khaliq, ${ }^{2} \mathrm{MG}$ Semple. 'Medical School, University of Liverpool, Liverpool, UK; ${ }^{2}$ Faculty of Health and Life Science, University of Liverpool, Liverpool, UK

\subsection{6/archdischild-2020-rcpch. 140}

Aim To evaluate the rate of influenza vaccination of 'at-risk' children and household members attending tertiary care clinics during the influenza season, 2018-19, and assess changes in trends by comparison with a similar study conducted in 2016-2017.

Methods Two medical students DG and RK produced an online survey, consisting of 10 questions focused on influenza vaccination, which was given to parents or guardians of children attending specified outpatient clinics over two weeks in January 2019.

Results 218 responses were split into at-risk children $(n=139)$ (defined by Immunisation against Infectious Disease: Influenza Chapter 19 revised 2018) and standard risk children $(n=79)$. Of the at-risk group, $57 \%$ had received influenza vaccination for the 2018/19 season - a 40\% increase from the 2016/17 influenza season. Rate of uptake was highest in patients attending Diabetes clinic (83\%) and lowest in those attending Rheumatology clinic (25\%). Only $48 \%$ of vaccinated patients lived in a household where all members of the household also had protection against influenza. The most used service to administer the influenza vaccination was general practice (41\%), and only $13 \%$ utilised tertiary care. Common reasons stated for non-vaccination were: 'did not believe it was necessary', 'not offered vaccination' and 'was not given enough information'.

Conclusion There has been a rise in influenza vaccination rates within the population over the two influenza seasons (20162019). However, from a public health perspective, the vaccination rates against seasonal influenza are continuously suboptimal $(<95 \%)$. Parents are not adequately informed about the influenza vaccination. In light of this, better parental education is needed, and we recommend clinicians take initiative to discuss vaccination with patients deemed 'at-risk' at every opportunity. We suggest that hospitals and other healthcare services utilise their waiting areas as an opportunity to raise awareness on the importance of influenza vaccination. It is hypothesised that offering vaccination within tertiary clinics may increase uptake in patients and their families.

\section{G170 OBESITY: IS IT A PROBLEM IN PRESCHOOL CHILDREN?}

S Buxton, T Skeath, A Dale. Paediatrics, Gateshead Health NHS Trust, Gateshead, UK

10.1136/archdischild-2020-rcpch. 141

The Gateshead Millennium Study found 28\% of children aged 6-8 were obese or overweight increasing to $1 / 3$ by age 10 . This reflects the national child measuring programme which describes $1 / 4$ of reception and $1 / 3$ year 6 children as overweight/obese. But is this too late for identification? Are children overweight and obese before this age?

Method Health visitors locally were trained to calculate and plot BMI on a specially made insert for the child health record to act as a visual aid to identify overweight children. BMI was collected over 6 months at the 2 year health check. Questionnaires were completed by health visitors to gather opinion around the issue and how we can improve identification and support families. Consenting families were interviewed to discover their opinion of how they felt going through the process, about weight in this population and what we could do to prevent overweight children.

Results 157 toddlers (mean age 2.3 years) were included with 132 BMI being calculated. 25 children with no BMI were felt to be unmeasurable due to compliance. $27 \%$ children were above overweight and obese centiles for BMI. 45 health visitor questionnaires were returned, and 12 parents individually interviewed. Health visitors and parents recognise that this is an issue and have similar opinions on the causes and how we can try to improve the situation. Parents felt that BMI was an acceptable tool for identification once explained. They felt if handled sensitively and with support this was an appropriate time for identification of children at risk of being overweight and obese.

Conclusion Overweight and obesity is an issue in children from as young as 2 years. This urgently needs to be addressed to prevent well known long term effects of excessive weight. Parents and health visitors agree and are a potential group to implement change.

\section{G171(P) ESTABLISHING THE USE OF AND OPTIMISING THE IMPACT OF THE HEADSSS PSYCHOSOCIAL ASSESSMENT TOOL FOR 12-16 YEAR-OLDS PRESENTING WITH SELF- HARM, OVERDOSE AND INTOXICATION TO THE PAEDIATRIC EMERGENCY DEPARTMENT}

WP Tasker, N Goodall, E Ironside, M Hartley. Children's Unit, NSECH, Cramlington, UK

\subsection{6/archdischild-2020-rcpch. 142}

\section{Aims}

- To introduce and standardise the use of the HEADSSS assessment.

- To use this information to promote integrated care; optimise social service referrals, coordinate care with ICTS (children's mental health team), prompt health promotion discussions and signpost to supporting services.

Methods HEADDSSS assessment forms were made available and awareness was raised via email and at induction. Reminders to use the assessment were made part of the morning team huddle. Monthly audits of completion rates were circulated via email.

The audit was extended to measure the completion of routine referral to social services including communication of the child sexual exploitation(CSE) risk, handover to ICTS and evidence of health promotion and signposting, after health promotion website cards were made available.

Results

- Completion rate rose from $12 \%$ to $80 \%$ over 4 audit cycles, then reduced to $53 \%$ in subsequent cycles.

- HEADSSS were less likely to be completed from 12:0015:00(33\%) and 18:00-21:00(46\%)- higher workload with no formal handover prompt at these times.

- $60 \%$ of $14-$ year-olds compared to $20 \%$ of 12 -year-olds had a completed HEADSSS.

- No evidence of social service referral for 14\%-18\% of eligible patients,(2 audit cycles). One patient had a significant CSE risk but no social service referral.

- $47 \%$ of patients were identified as having 'no safeguarding issue' on their discharge letter. 
- No formal handover of HEADSSS to ICTS team.

- No documentation of health promotion.

Conclusion HEADSSS had been introduced effectively by circulating completion rates but use has not been maintained reliably. Suggested improvements include focusing on younger patients and further handover prompts.

The process of HEADSSS assessment, social services referral and ICTS review is discoordinated. Suggested improvements include educating clinicians, form adjustments, comprehensive information leaflets and linking local organisations such as SORTED (substance misuse) and the 'early-help-hub' (family support) to address psychosocial needs and prompt health promotion.

\section{G172(P) MATERNAL ATTITUDES TO SAFE INFANT SLEEPING PRACTICES}

${ }^{1} \mathrm{~N}$ O'Brien, ${ }^{2} \mathrm{C}$ McGarvey, ${ }^{2} \mathrm{~K}$ Hamilton, ${ }^{1} \mathrm{~B}$ Hayes. ${ }^{1}$ Neonatology, The Rotunda Maternity Hospital, Dublin, Ireland; ${ }^{2}$ National Paediatric Mortality Register, The Children's University Hospital, Temple St, Dublin, Ireland

\subsection{6/archdischild-2020-rcpch.143}

Aims Educational campaigns have resulted in a $50-75 \%$ reduction in Sudden Infant Death Syndrome (SIDS) worldwide since the 1990's. Current Irish and UK SIDS rates are 0.3/1000 live births. Despite these successes, SIDS accounts for up $40 \%$ to post-neonatal infant mortality.

Risks include prone or side sleeping, co-sleeping, excess bedding, prematurity, low birth weight and smoke exposure. Protective factors include breastfeeding, room-sharing and immunisations. Sleeping bags and cardio-respiratory monitors are not protective. Sleeping nests are harmful.

\begin{tabular}{ll} 
Abstract G172(P) Table 1 & \\
\hline Maternal Demographics & $\mathrm{n}=450$ \\
\hline Age & \\
$<25$ years & $9.4 \%$ \\
$>40$ years & $8.9 \%$ \\
Parity & \\
Primigravida & $45.3 \%$ \\
$\geq$ Gravida 3 & $61.4 \%$ \\
Marital Status & \\
Married & $62.4 \%$ \\
Co-habiting & $15.3 \%$ \\
Single & $21.5 \%$ \\
Education & \\
Further education & $76 \%$ \\
Higher secondary school & $15.3 \%$ \\
Lower secondary school & $5.2 \%$ \\
Primary school & $1.6 \%$ \\
Feeding & \\
Exclusive breastfeeding & \\
Combined feeding & $62 \%$ \\
Formula feeding & $10.2 \%$ \\
Bedding & $27.8 \%$ \\
Cleeping bags & \\
Pillows & $26.8 \%$ \\
Sleeping pods & $11.7 \%$ \\
\hline & $9.5 \%$ \\
\hline
\end{tabular}

In $2000,60 \%$ of mothers smoked, $13 \%$ co-slept, and 54\% of infants slept supine. We wished to reassess maternal knowledge and associated variables regarding safe infant sleeping practices.

Methods A cross-sectional survey was completed with mothers prior to discharge in a tertiary maternity hospital that has 8,000 deliveries annually. Exclusion criteria included previous miscarriage or SIDS, and infants admitted to the neonatal unit.

Results 450 mothers were recruited. Demographics are given below. $8.9 \%$ smoked antenatally, with $20 \%$ of infants exposed to household smoke. $84.6 \%$ of infants slept supine, with $15.4 \%$ sleeping either side or prone. $67.4 \%$ used a monitor. $31.7 \%$ used a soother. $44.4 \%$ had health insurance, and $20.2 \%$ had a medical card.

Mothers $<25$ years were more likely to smoke $(31 \%$ Vs $6 \%, \mathrm{p}<0.001)$, and less likely to breastfeed $(50 \%$ Vs $75 \%$, $\mathrm{p}<0.01$ ). Age had no interaction with sleeping position. Further analysis on the effect of maternal age, education, health insurance and ethnicity is pending.

Conclusion Globally there has been a reduction in SIDS and an improvement in infant sleeping practices. However, deprived families are over-represented in SIDS deaths, and campaigns need to specifically target this cohort. Furthermore, parents need to be educated on evidence-based practices, as many devices marketed to reduced SIDS have no proven benefit, and others are harmful.

\section{G173(P) HEALTH BENEFITS OF EXPOSURE TO WOODLAND AND THE BENEFITS OF FOREST SCHOOLS FOR CHILDREN AND THOSE WITH ADDITIONAL NEEDS}

F Finlay, S Lenton. Community Child Health, Virgin Care, Bath, UK

\subsection{6/archdischild-2020-rcpch.144}

Aims There is an increasing interest in prevention and population health following the publication of the NHS Long-Term Plan and Advancing Our Health, Prevention in the 2020's. This paper examines the existing evidence on the health benefits of exposure to woodland and the benefits of forest schools for children and those with additional needs.

Method Literature review.

Results The adult literature supports the theory that exposure to natural environments are health promoting with evidence that forest bathing (Shinrin-yoku) can:

- Reduce blood pressure and heart rate

- Reduce urinary adrenaline and serum cortisol

- Improve mental well-being by reducing anxiety, depression, fatigue

- Positively affect the immune system by increasing natural killer cells and intracellular anticancer proteins

- Reduce recovery time after surgical intervention.

The physiological benefits have been attributed to psychological benefits acting through the hypothalamic-pituitary axis and the impact ofphytoncides (naturally occurring aromatic volatile substances emitted by trees) having antioxidant and anti-inflammatory effects. As yet there are few studies on health benefits for children and young people.

In contrast, there are many observational studies describing the benefits of Forest schools on education outcomes. The Forest School philosophy originated in Scandinavia during the 